\title{
HETEROGENEIDADE DO DESEMPENHO DE EMPRESAS EM AMBIENTES TURBULENTOS
}

\section{RESUMO}

Pesquisas empíricas sobre a heterogeneidade do desempenho das firmas geralmente modelam os efeitos do ano, da indústria ou setor, e das características da empresa. Neste artigo, são utilizados três indicadores para compor uma medida multivariada da performance das firmas que operam no Brasil. Argumenta-se que somente um indicador talvez não seja capaz de captar os efeitos de um ambiente turbulento. Dados sobre uma amostra representativa de firmas de capital aberto, atuantes em 15 setores da economia, foram coletados por um período de cinco anos (1998-2002). Os resultados convergem para estudos anteriores ao atribuírem maior importância aos fatores associados às características da firma. Contudo, os efeitos transientes da indústria apresentam maior contribuição na heterogeneidade do desempenho do que seus efeitos estáveis. Isso sugere que os setores mais atrativos "amortecem" os impactos negativos da turbulência ambiental e que características da estrutura de capital das empresas parecem estar associadas à eficácia desse "amortecimento".

\section{Rodrigo Bandeira-de-Mello}

Univali

\section{Rosilene Marcon}

Univali

\begin{abstract}
Empirical researches on firm performance heterogeneity usually model year, industry and firm effects to assess their contributions to total firm performance variation. In this paper, we use three indicators to compose a performance measure of firms operating in Brazil. We argue that a single indicator is not capable of taking into account the effects of a turbulent environment. Data on firm performance were collected for 177 listed firms in 15 industries, for a 5-year period (1998-2002). We found that, similar to previous studies that used a single indicator for performance, firm effects accounted for most of the variation found in data. Conversely, the amount of total variation associated with transient industry effects was greater than the stable effects. Results also indicate that attractive industries "buffer" negative effects of environmental turbulence and the characteristics of firm capital structure appear to be associated to the efficacy of such "buffering".
\end{abstract}

PALAVRAS-CHAVE Heterogeneidade das firmas, decomposição da variância, desempenho das firmas, ambiente turbulento, efeitos transientes e estáveis da indústria.

KEYWORDS Firm heterogeneity, variance decomposition, firm performance, turbulent environments, transient and stable industry effects. 


\section{INTRODUÇÃO}

A compreensão da heterogeneidade e dos mecanismos pelos quais diferentes níveis de desempenho são obtidos e sustentados pelas empresas são temas abordados nas agendas de pesquisa em estratégia. Estudos empíricos que investigam a heterogeneidade têm servido para fundamentar as principais perspectivas teóricas sobre fontes de vantagem competitiva sustentável, como a perspectiva porteriana, derivada da área de organização industrial (OI), e a resource-based view (RBV). Sem estabelecer proposições de relações causais, a variância observada do desempenho das firmas é decomposta, e seus componentes são associados a fatores conceitualmente derivados das perspectivas teóricas, tais como a indústria ou setor no qual a firma opera, e os seus recursos e capacidades especiais.

Dentre os principais estudos, podem ser citados os trabalhos seminais de Schmalensee (1985), Rumelt (1991), Roquebert, Phillips e Westfall (1996), McGahan e Porter (1997, 2002) e Hawawini, Subramanian e Verdin (2003). Todos foram desenvolvidos no contexto da economia norte-americana e utilizaram um indicador de rentabilidade operacional (a razão entre lucro operacional e os ativos totais) como medida de desempenho.

Em um ambiente turbulento como o do Brasil, a heterogeneidade do desempenho das empresas ainda é pouco compreendida. Desde a década de 1980, choques econômicos provocaram alterações nas regras que regem as relações contratuais entre firmas, no que tange aos sistemas de tributação, congelamento de preços, variações significativas nas políticas monetárias e de controle à inflação (Baer, 1996). Em face dessa instabilidade ambiental, seria de esperar que a estrutura da variância observada nas empresas brasileiras fosse diferente. No entanto, Brito e Vasconcelos (2003) encontraram uma estrutura similar à relatada na literatura internacional.

Este artigo avança em relação à análise da heterogeneidade do desempenho em ambientes turbulentos pelo fato de o modelo teórico captar os efeitos da turbulência ambiental por meio da mensuração do desempenho de forma multivariada. Defende-se que o efeito das características do ambiente brasileiro na distribuição da performance das firmas é captado de forma distinta em função da métrica utilizada. Em países como o Brasil, onde as variáveis macroeconômicas estão fortemente baseadas na política monetária - que se caracteriza por um constante controle da inflação -, a mensuração do desempenho das empresas deve considerar indicadores capazes de captar os efeitos dessa política.

Neste estudo, a mensuração multivariada do desempenho é realizada por indicadores de rentabilidade operacional, de geração de valor para os proprietários das empresas e das expectativas dos investidores. As próximas seções apresentam os trabalhos téorico-empíricos mais relevantes para este estudo e os aspectos metodológicos. Em seguida, discutem-se e analisamse os resultados e apresentam-se as conclusões.

\section{ANÁLISE DA HETOREGENEIDADE PELA DECOMPOSIÇÃO DO DESEMPENHO}

A análise da dispersão ou da heterogeneidade do desempenho de empresas pela decomposição da variância teve sua origem no trabalho de Schmalensee (1985), seguido por Rumelt (1991), Roquebert, Phillips e Westfall (1996), McGahan e Porter $(1997,2002)$ e Hawawini, Subramanian e Verdin (2003), para citar alguns autores.

A variância do desempenho das empresas é decomposta ou partilhada, e cada componente corresponde a uma fração da variância total. Nesse tipo de modelagem, as componentes são fatores, ou classe de efeitos, cujos níveis classificam as empresas da amostra em grupos distintos. Por exemplo, um fator modelado é a indústria, ou o setor no qual a empresa opera. Os níveis desse fator são os diferentes setores amostrados, como alimentos, siderurgia e telecomunicações. A quantidade relativa da variância total observada no desempenho das empresas da amostra associada à componente indústria, ou efeito indústria, representa a contribuição das diferenças entre a performance média de cada nível na descrição da variância total. O efeito indústria é explicado pela organização industrial (Caves e Porter, 1977; Porter, 1980; Oster, 1990), sendo o mesmo raciocínio utilizado para calcular a contribuição das diferenças entre características específicas das firmas (Wernefelt, 1984; Barney, 1986; Peteraf, 1993; Dosi, Nelson e Winter, 2000).

Em geral, os fatores modelados incluem a indústria ou setor no qual a firma opera (efeitos da indústria); o grupo controlador ao qual a firma pertence, quando ela é uma unidade de negócios de um grupo diversificado (efeitos do grupo controlador); ciclos e choques econômicos, que afetam todas as firmas em determinado ano (efeitos do ano); e características específicas e idiossincráticas da firma, que incluem diferenças 
entre posicionamento competitivo, capacidades e recursos (efeitos da firma).

O estudo seminal de Schmalensee (1985) utilizou uma base de dados cross sectional de empresas manufatureiras. Cerca de $20 \%$ da variância total, e quase a totalidade explicada pelo modelo, associamse às características da indústria. Quanto às outras variáveis do modelo, os efeitos do grupo controlador se mostraram significantes; e os efeitos da participação de mercado, uma forma de analisar os efeitos da firma, captaram menos de $1 \%$ da variância total.

Rumelt (1991) aprimorou o estudo de Schmalensee (1985), utilizando dados para um período de quatro anos. Isso possibilitou a modelagem do efeito das flutuações macroeconômicas, bem como os efeitos idiossincráticos das firmas, estáveis ao longo dos anos. Aos efeitos da firma se associaram cerca de 34 a $46 \%$ da variação observada da performance, contra cerca de 8 a 18\%, dessa mesma variação, referentes aos efeitos estáveis da indústria. Os resultados também apontaram para uma contribuição não significativa dos efeitos macroeconômicos num determinado ano, mas cerca de 9 a 10\% da variância total observada estão associados à variação das diferenças entre as rentabilidades médias dos setores, ao longo dos anos analisados (efeitos transientes da indústria-ano). ${ }^{1}$

Outro estudo empírico de referência é o de McGahan e Porter (1997). Os autores utilizaram métodos estatisticamente mais robustos do que seus antecessores. Diferentemente de Schmalensee (1985) e Rumelt (1991), a amostra foi ampliada para todos os setores, excluindo-se o setor financeiro e as estatais, e cobrindo um período de 14 anos. Os autores constataram que cerca de $19 \%$ da variação encontrada nos dados se referiram ao efeito da indústria e cerca de $32 \%$ foram atribuídos aos efeitos da firma.

Em McGahan e Porter (2002), os autores elaboraram um design em que as correlações seriais do erro e a covariância entre os efeitos foram modeladas, o que permitiu atenuar as limitações dos pressupostos do método da decomposição da variância sobre a aleatoriedade dos resíduos e independência entre os efeitos. Após serem ajustadas para a correlação serial, as contribuições relativas do ano, indústria, grupo controlador e da firma foram, respectivamente, de $0,4 \%, 10,3 \%, 11,6 \%$ e $36 \%$, em um modelo que explicou $58 \%$ da variância observada. Dentre as principais conclusões, observam-se as seguintes: a) os efeitos da firma são mais importantes do que os efeitos do ano, da indústria e do grupo controlador; b) os efeitos do ano correspondem a uma pequena fração da variância observada; c) as importâncias relativas dos efeitos do ano, da indústria, firma e grupo controlador diferem ao longo dos setores analisados; d) os efeitos da indústria e do grupo controlador são correlacionados, visto que a decisão de entrada em uma indústria está relacionada à sua atratividade; e) os efeitos da indústria, do grupo controlador e do segmento de negócio são relacionados temporalmente, o que implica que desempenhos diferentes da média tendem a se refletir no ano seguinte.

No Brasil, Brito e Vasconcelos (2003) utilizaram um modelo semelhante ao de Rumelt (1991), porém sem os efeitos do grupo controlador e da covariância. Os resultados apontaram que os efeitos da firma são os que correspondem à maior parte da variância observada $(52,3 \%)$, seguidos dos efeitos da indústria $(7,1 \%)$ e indústria-ano $(2,1 \%)$. Os autores concluíram que a turbulência ambiental brasileira não produz uma estrutura de composição da variância do desempenho das firmas, peculiar a esse tipo de ambiente.

Hawawini, Subramanian e Verdin (2003) questionaram o uso de medidas contábeis de rentabilidade, calculadas a partir da razão entre lucros e ativos, em favor de medidas baseadas em valor. Para esses autores, "se o propósito da estratégia [...] é gerar criação sustentável de valor que ocorre somente quando as firmas geram retornos maiores do que o custo de capital, então as medidas utilizadas deveriam captar tal desempenho econômico" (Hawawini, Subramanian e Verdin, 2003, p. 1).

Os autores utilizaram um modelo similar ao de Rumelt (1991). A performance foi mensurada pela rentabilidade dos ativos, pelo lucro econômico e pelo valor total de mercado. Porém, apesar de suas suposições iniciais, concluíram que o uso de medidas contábeis em estudos anteriores não foi limitante e que, independentemente da medida utilizada, os resultados convergiram para os de estudos anteriores de decomposição da variância.

De uma forma geral, os estudos empíricos de decomposição da variância observada do desempenho das firmas apresentam resultados convergentes, inclusive para ambientes turbulentos. Os resultados obtidos indicam que o efeito da firma é o mais importante, associado a mais de um terço da variância observada, seguido dos efeitos da indústria e do grupo controlador. O efeito do ano corresponde a porções reduzidas da variância observada. Isso significa que as diferenças entre as firmas quanto aos seus recursos, capacidades 
gerenciais e posicionamento competitivo são os fatores mais importantes para distinguir firmas com bons e maus desempenhos. Já as características ambientais dos setores estão em segundo lugar, e os efeitos macroeconômicos inerentes a cada ano do período não foram significativos. Os efeitos da firma que fundamentam empiricamente a RBV (Wernerfelt, 1984; Barney, 1986; Peteraf, 1993; Dosi, Nelson e Winter, 2000) continuam superiores, mesmo em ambientes turbulentos (Brito e Vasconcelos, 2003).

Com exceção de Hawawini et al. (2003), o desempenho é medido por um indicador de rentabilidade operacional. Defende-se neste artigo que a compreensão da heterogeneidade do desempenho é influenciada pela métrica utilizada para mensurar o construto performance. Por isso, em ambientes turbulentos, como o do Brasil, o modelo deve ser especificado para acomodar os efeitos da turbulência nas diferentes facetas do desempenho das firmas. Neste artigo, ao considerar mais de um indicador de performance, incrementa-se a compreensão sobre a natureza das diferenças no desempenho entre as empresas que operam no Brasil.

\section{INDICADORES DE DESEMPENHO}

A falta de consenso quanto aos objetivos da empresa polariza uma discussão no contexto da estratégia sobre a mensuração do desempenho. Há os que defendem que uma organização deve atender a todos os agentes envolvidos no negócio - os stakeholders - e não somente aos objetivos dos acionistas. Outros advogam que as empresas devem primordialmente servir aos acionistas - os shareholders -, caso contrário falham em servir à sociedade. Mesmo que se assuma o pressuposto de que o objetivo da firma é a maximização da riqueza dos acionistas a longo prazo, a definição do melhor indicador para mensurar esse desempenho não é uma decisão simples. O número de indicadores existentes é muito elevado: retorno dos ativos, retorno do capital próprio, retorno para o investidor, Q de Tobin, entre outros indicadores.

Para Bacidore et al. (1997), uma medida de performance apropriada avalia como a estratégia afeta o valor do acionista, medida pela taxa de retorno do capital investido, ajustado ao risco do investidor. Para os autores, uma boa medida de performance financeira deveria refletir a capacidade da empresa em gerar lucro operacional, dada a quantia de capital investida.
Porém, os provedores de recursos devem ao menos ganhar o seu custo de oportunidade sobre o capital investido.

A escolha dos indicadores depende da proposta do estudo. As medidas contábeis são melhores do que medidas baseadas no mercado, ao avaliar-se o desempenho da empresa no contexto de todos os stakeholders. Contudo, como defendem Wernerfelt e Montgomery (1988), medidas contábeis de rentabilidade não são capazes de considerar a expectativa do mercado e as diversas abordagens do risco, melhor captado pelos indicadores de mercado.

De forma geral, podem-se classificar os múltiplos indicadores de desempenho em categorias tais como: a) os indicadores de valor, quando o interesse for medir a criação de valor para os acionistas, como o Market Value Added (MVA), o Economic Value Added (EVA); b) os indicadores contábeis, como return on equity (ROE) e return on assets (ROA); c) os indicadores de desempenho ajustados ao mercado, como o Índice Preço/ Valor Patrimonial (P/VPA) e Preço/Lucro (P/L).

A utilização de múltiplos indicadores permite captar a influência de diversos agentes sobre o desempenho da empresa, minimizando o erro de mensuração do construto desempenho. Com o uso de métricas de diferentes abordagens, pode-se avaliar o efeito de agentes específicos sobre o desempenho da empresa, sejam estes operacionais, como a redução dos custos ou o aumento das vendas; financeiros, como o custo de capital ajustado ao risco, o aumento da taxa de juros e captações de recursos em outros países; fatores de mercado, como a expectativa dos investidores quanto ao desempenho futuro da empresa e da economia; e também, atender aos diferentes pontos de vista existentes, sejam dos investidores, dos credores, dos clientes, dos funcionários ou dos administradores.

\section{MÉTODO E DADOS}

As empresas que compuseram a amostra deste trabalho foram as de capital aberto, listadas na Bovespa e publicadas na base Economatica ${ }^{\circledR}$. Além de fornecerem dados mais confiáveis do que empresas de capital fechado, sofrem múltiplos efeitos da turbulência ambiental no seu desempenho.

Neste estudo, foram considerados somente 15 setores, aqueles com número de empresas suficientes para adequação ao modelo utilizado. As instituições financeiras não foram incluídas devido ao seu alto grau de 
alavancagem, o que compromete a análise dos indicadores de desempenho. Além disso, foram consideradas apenas firmas com faturamento superior a US $\$ 10$ milhões - para cada indicador de desempenho -, cujas séries fornecessem dados de pelo menos três dos cinco anos analisados (1998-2002). Para cada firma específica $k$, de uma indústria específica $i$, em cada ano $t$, foram calculados três indicadores de desempenho: o retorno operacional, calculado pela razão entre o lucro operacional, antes dos juros, depreciação e imposto de renda, e o ativo total da firma (LO_AT); a criação ou destruição de valor ao acionista, na medida em que se desconta o custo de capital do retorno sobre o capital próprio (ROE_KE); as expectativas do mercado sobre o futuro da firma, refletidas pela razão entre o preço da ação, no fechamento do último dia útil do ano, e o seu valor patrimonial (P_VPA).

A análise de componentes principais (ACP) reduziu os três indicadores de desempenho a uma medida multivariada $r_{i, k, t}{ }^{2} \mathrm{O}$ desempenho $r_{i, k, t}$, de uma firma $k$, que atua em uma indústria $i$, em um determinado ano $t$, foi modelado pela Equação 1 .

$$
r_{i, k, t}=\mu+\gamma_{t}+\alpha_{i}+\delta_{i, t}+\phi_{k}+\varepsilon_{i, k, t}
$$

sendo que,

$$
r_{i, k, t}=R O E_{-} K E_{i, k, t}+P_{-} V P A_{i, k, t}+L O_{-} A T_{i, k, t}
$$

A Equação 1 especifica que o desempenho anual de cada empresa $k$ é composto pela média geral do conjunto de dados $(\mu)$, acrescido das seguintes contribuições:

a) Efeitos do ano $\left(\gamma_{t}\right)$ : refletem a diferença entre o desempenho médio de todas as empresas em um determinado ano $t(t=1998,1999, \ldots, 2002)$ e a média geral $\mu$. Os efeitos do ano resultam de flutuações macroeconômicas que afetam todas as firmas em um determinado ano.

b) Efeitos da indústria $\left(\alpha_{i}\right)$ : refletem a diferença entre o desempenho médio de todas as firmas de uma determinada indústria $i(i=1,2, \ldots, 15)$ e a média geral $\mu$. Os efeitos de uma indústria resultam das características de sua estrutura industrial, sendo eles: a presença de barreiras de entrada, a diferenciação de produto e o poder de barganha de fornecedores e clientes. Estes são considerados efeitos estáveis, pois afetam todas as firmas de uma indústria ao longo do período analisado.

c) Interação indústria-ano $\left(\delta_{i, t}\right)$ : estes termos captam as variações anuais das diferenças entre os desempenhos médios das indústrias analisadas. A existência desses efeitos transientes significa que os efeitos do ano afetam diferentemente as indústrias, como: os efeitos cíclicos de determinados produtos e as diferentes sensibilidades à variação do nível de atividade macroeconômica ou safra anormal de um produto em um ano.

d) Efeitos da firma $\left(\phi_{k}\right)$ : refletem a diferença entre o desempenho médio de cada firma $k(k=1,2, \ldots, 177)$ ao longo do período analisado e a média geral $\mu$. Estes são considerados efeitos estáveis, específicos de cada firma, advindos de suas idiossincrasias: a explotação de recursos; as diferenças nos processos organizacionais, nos níveis de eficiência e no posicionamento competitivo.

e) Termo de erro $\left(\varepsilon_{i, k, t}\right)$ : são os resíduos, aleatórios e independentes, calculados pela diferença entre o valor esperado da variável dependente, calculado a partir dos efeitos modelados, e o valor observado.

Os fatores especificados no modelo - efeitos do ano, indústria, interação indústria-ano e firma - são considerados efeitos aleatórios (random effects model). Isso significa que os níveis da cada fator - os cinco anos, os 15 setores e as 177 firmas - foram retirados aleatoriamente de uma população de níveis. Esse pressuposto permite que a variância do termo dependente da Equação 1 seja composta pelas variâncias associadas a cada fator modelado, denominadas componentes de variância. Dessa forma, a porcentagem, da variância total de $r_{i, k, t}$, associada a cada componente reflete a importância relativa do respectivo fator na descrição da heterogeneidade do desempenho.

O método de componentes de variância (COV) calcula estimadores não viesados para as variâncias populacionais dos fatores, conforme descrito na Equação 3, por meio de técnicas tais como a ANOVA e a Máxima Verossimilhança - ML (Searle, 1971).

$\sigma^{2} r=\sigma_{\gamma}^{2}+\sigma_{\alpha}^{2}+\sigma^{2} \delta+\sigma_{\phi}^{2}+\sigma_{\varepsilon}^{2}$

A desvantagem do método dos componentes de variância é a não geração de estimadores confiáveis para testar a significância de cada efeito. Para atenuar essa desvantagem, Rumelt (1991), McGahan e Porter (1997), Hawawini, Subramanian e Verdin (2003) e Brito e Vasconcelos (2003) utilizaram a regressão ANOVA, de forma hierárquica, para testar a significância do incremento no $\mathrm{R}^{2}$ ajustado devido à inclusão de um novo fator no modelo. Essa técnica de regressão ANOVA considera todos os efeitos como fixos (fixed model), e a ordem de inclusão importa, na medida em que os primeiros tendem a captar mais variância do que os últimos. 
Convém ainda salientar alguns aspectos das decisões tomadas acerca do método e dos dados utilizados. A exemplo de Hawawini, Subramanian e Verdin (2003) e Brito e Vasconcelos (2003), não foram incluídos no modelo os efeitos do grupo controlador (corporate effects). Hawawini, Subramanian e Verdin (2003) alegam que as evidências empíricas desses efeitos são inconclusivas. Neste estudo, a amostra utilizada contém um número reduzido de unidades de negócio, pertencentes a grupos diversificados.

Outro ponto importante diz respeito aos pressupostos de aleatoriedade e independência dos resíduos e dos fatores. Rumelt (1991) registrou não ter encontrado correlação serial, ao passo que McGahan e Porter (1997) registraram uma correlação serial de primeira ordem que não gerou resultados divergentes dos estudos anteriores; e covariância entre efeitos da indústria e do grupo controlador. Neste estudo, a exemplo de Brito e Vasconcelos (2003), não se considerou a existência de correlação serial, apesar de que parte dela, de acordo com McGahan e Porter (1997), pode ser captada pelos efeitos transientes indústria-ano. A questão da covariância entre efeitos da indústria e do grupo controlador também não foi considerada pela não inclusão desses no modelo.

Finalmente, deve-se comentar sobre o tratamento dado aos outliers. O método COV analisa a variabilidade observada nos dados. Os outliers podem influenciar consideravelmente os resultados. Hawawini, Subramanian e Verdin (2003) verificaram o impacto da retirada, da amostra, de firmas com desempenhos extremos e verificaram que uma proporção significativa da variância explicada pelos efeitos da firma se deve à presença de outliers. Neste artigo, primeiramente foi feita uma análise "microscópica" da base de dados para identificar valores aberrantes, sendo cada caso analisado separadamente. As firmas aqui excluídas apresentavam características peculiares que influenciam os resultados dos indicadores de desempenho, como problemas de reestruturação financeira, fusões e processos de falência. Em seguida, procedeu-se a uma análise multivariada dos outliers, retirando-se da amos- tra as empresas que apresentaram desvios da média $\mu$ superiores a mais ou menos três desvios padrão, para cada indicador de desempenho, pois esse valor é superior ao que Hair et al. (1995) sugerem como 2,5 desvios padrão.

\section{EVIDÊNCIAS EMPÍRICAS DO DESEMPENHO DE EMPRESAS EM AMBIENTES TURBULENTOS}

Ao analisar o número de observações para cada variável dependente original, por nível do fator indústria, para as 177 firmas, ao longo dos cinco anos, constatou-se que, para a variável LO_AT, o número médio de empresas em cada setor foi de 56; para o ROE_KE teve-se uma média de 55 empresas, e para $\mathrm{P}_{-}$VPA, a média foi de 51 empresas. O setor que apresentou o maior número de empresas para todos os indicadores foi o de telecomunicações, e o de mineração foi o menor.

As estatísticas descritivas apresentadas na Tabela 1 revelam a baixa performance das empresas da amostra no período de cinco anos, tanto no nível operacional (LO_AT $=2,13 \%$ ) como em valor adicionado ao acionista (ROE_KE $=-23,79 \%$ ); e uma desvalorização no preço de mercado da ação em relação ao seu valor patrimonial $\left(P_{-}\right.$VPA $\left.=0,8176\right)$.

A diferença entre as variâncias dos indicadores operacionais (LO_AT) e financeiros (ROE_KE) sugere que, quando se considera a estrutura e o custo de capital das empresas, a dispersão do desempenho aumenta. Diferenças nos níveis de endividamento das empresas, no acesso às fontes de captação ou na gestão financeira na rolagem das dívidas, por exemplo, parecem ser discriminantes do nível desempenho.

Com exceção da variável P_VPA, os indicadores apresentam assimetria negativa, revelando a influência de retornos extremos inferiores. A análise da curtose revela distribuições leptocúrticas, com as firmas tendendo a apresentar desempenhos tanto extremos como próximos à média, em detrimento de desempenhos a uma distância regular da média.

Tabela 1 - Medidas descritivas das variáveis dependentes.

\begin{tabular}{|c|c|c|c|c|}
\hline INDICADORES & MÉDIA & VARIÂNCIA & ASSIMEIRIA & CURTOSE \\
\hline LO_AT & 0,0213 & 0,01322 & $-1,789$ & 9,942 \\
\hline ROE_KE & $-0,2379$ & 0,17770 & $-3,547$ & 18,753 \\
\hline P_VPA & 0,8176 & 0,81939 & 2,255 & 15,485 \\
\hline
\end{tabular}


O próximo passo da análise é a redução dos indicadores de desempenho a uma medida multivariada por meio da ACP (Análise dos Componentes Principais). Com relação à correlação das variáveis, todos os coeficientes foram significativos nos níveis usuais ( $p<0,0001$ ), sendo que o P_VPA possui os menores coeficientes. Isso mostra desalinhamento entre as expectativas dos investidores e os retornos auferidos pelas empresas, de certa forma comum em países emergentes, onde o preço das ações segue o comportamento do mercado e não o desempenho da empresa.

As variáveis se mostraram adequadas para a redução pela ACP e a solução inicial não rotacionada gerou apenas uma componente principal com eigenvalue superior a 1. Essa componente extraiu 55,63\% da variância total.

No tocante à correlação de cada variável com a componente extraída, esta última (Fatorl) foi utilizada como variável dependente no modelo da Equação 1, obtendo-se os seguintes valores para cada indicador: 0,855(LO_AT); 0,859(ROE_KE); 0,448(P_VPA). A Tabela 2 apresenta os resultados encontrados com as evidências de Brito e Vasconcelos (2003), cujos autores fizeram um estudo similar no Brasil que mensurou desempenho por um indicador operacional (LO_AT).

Vê-se ainda na Tabela 2 que, quanto maior a porcentagem, maior a contribuição do fator para a compreensão das diferenças observadas no desempenho. Ambos os estudos apresentaram estruturas de variância similares. Os efeitos da firma são os mais importantes - associam-se a cerca de 43 a 54\% da variância total do desempenho -, seguidos das contribuições dos efeitos da indústria e do ano, nessa ordem. Isso significa que, para discriminar bons e maus desempenhos, as idiossincrasias das empresas, seus recursos essenciais e suas capacidades organizacionais são mais importantes do que as estruturas setoriais das indústrias nas quais estão inseridas. Quanto às influências macroeconômicas, que afetam todas as firmas num ano em particular, tornam-se praticamente desprezíveis. A semelhança entre as duas estruturas de variância sugere que a medida multivariada do desempenho não revelou as peculiaridades do ambiente turbulento.

Duas divergências podem ser ressaltadas. A primeira diz respeito à variância explicada pelo modelo de Fator 1 , de $50 \%$ a $52 \%$ da variância total observada. Esta, apesar de próxima dos valores encontrados nos estudos internacionais, é inferior em cerca de $10 \%$ ao valor encontrado em Brito e Vasconcelos (2003). Considerando que a mensuração multivariada atenua o erro de mensuração do construto "desempenho da empresa", a redução na variância explicada indica que novos fatores devem ser utilizados na especificação do modelo.

A segunda divergência mostra que existem diferenças na relação entre os efeitos transientes e estáveis da indústria, pois quando o desempenho é mensurado por um indicador operacional (LO_AT), os efeitos estáveis são superiores aos efeitos transientes. Já no modelo de Fator1, os efeitos transientes são quase o dobro dos efeitos estáveis da indústria. Esses resultados indicam que os efeitos do ano são importantes à medida que afetam distintamente o desempenho médio dos setores. Já na análise dos componentes de variância das variáveis originais de Fator 1 fornece informações adicionais sobre a natureza dos efeitos transientes da indústria.

Na Tabela 3, os resultados do indicador LO_AT convergem para os do modelo de Brito e Vasconcelos (2003), já expostos na Tabela 2. O indicador ROE_KE merece destaque, pois seu modelo explica pouco mais de $31 \%$ da variância observada; apresenta a maior importância para os efeitos do ano e para os efeitos transientes da indústria (de 3 a $4 \%$ e de 3 a $5 \%$ da variância total observada, respectivamente), e menor

Tabela 2 - Decomposição da variância do desempenho em ambientes turbulentos.

\begin{tabular}{|l|c|c|c|c|}
\hline \multirow{2}{*}{ FATORES } & \multicolumn{2}{|c|}{ VAR. DEP. FATOR1 } & \multicolumn{2}{c|}{ BRITO E VASCONCELOS (2003) } \\
\cline { 2 - 5 } & ANOVA & ML & ANOVA & ML \\
\hline Ano & $0,78 \%$ & $1,01 \%$ & $0 \%$ & $0 \%$ \\
\hline Indústria & $2,91 \%$ & $2,54 \%$ & $7,1 \%$ & $4,3 \%$ \\
\hline Indústria-ano & $3,77 \%$ & $4,68 \%$ & $2,1 \%$ & $2,4 \%$ \\
\hline Firma & $43,49 \%$ & $44,39 \%$ & $52,3 \%$ & $64 \%$ \\
\hline Modelo & $50,96 \%$ & $52,61 \%$ & $61,50 \%$ & $39 \%$ \\
\hline Erro & $49,04 \%$ & $47,39 \%$ & $38,5 \%$ & $39,3 \%$ \\
\hline
\end{tabular}

Nota: Os totais podem não coincidir devido ao arredondamento. ANOVA e ML são técnicas para a estimação das componentes de variância. 
valor para os efeitos estáveis da indústria (1\% dessa variância).

Em ambientes turbulentos, as características estáveis da estrutura setorial pouco contribuem para discriminar o desempenho mensurado pelo ROE_KE. Por outro lado, a forma como cada setor reage à turbulência ambiental (efeitos transientes) é mais importante do que suas características estáveis. Do ponto de vista da construção de valor para o acionista, não existe "o setor certo para investir" quando se trata de suas características estáveis. Porém, podem existir aqueles que "sofrem menos" ou "amortecem" os efeitos das hostilidades macroeconômicas de um determinado ano, como os setores que possibilitam às empresas utilizar estruturas de capital "blindadas", menos susceptíveis às variações anuais. ${ }^{3}$

Já para o indicador P_VPA, os efeitos estáveis (3-4\%) são mais importantes do que os efeitos transientes da indústria (2\%), pois a racionalidade do investidor na precificação das ações no mercado se baseia nas características específicas e estáveis de cada setor. Aqui, segue-se a lógica de "setores que são sempre bons investimentos". Os investidores parecem não se preocupar com uma análise mais cuidadosa do risco dos setores devido aos efeitos distintos de uma determinada variação macroeconômica.
Os fatores modelados na Equação 1 podem ser tomados como fixos e o modelo linear pode ser regredido de forma hierárquica. A intenção é verificar o incremento do poder explicativo de cada fator, inserindo-os um a um. Na regressão hierárquica, devido à forma de partição das somas dos quadrados, somente a variação não explicada pelo modelo precedente é regredida pelos novos fatores. A ordem de inserção dos fatores seguiu o critério adotado em estudos anteriores, e os resultados podem ser visualizados na Tabela 4 .

Os incrementos de $\mathrm{R}^{2}$-ajustado convergem para os resultados da decomposição da variância e são similares aos de Brito e Vasconcelos (2003). As contribuições dos efeitos de um ano em particular sobre todas as firmas não se mostraram significativas, porém os demais fatores apresentaram contribuição significativa na variância explicada nos níveis usuais de significância.

\section{CONSIDERAÇÕES FINAIS}

Mesmo em ambientes turbulentos como o do Brasil, os efeitos da firma continuam sendo preponderantes sobre os demais, e a turbulência ambiental parece não afetar a natureza das diferenças de desempenho. A

Tabela 3 - Decomposição da variância do desempenho: variáveis originais de Fator1.

\begin{tabular}{|l|c|c|c|c|c|c|}
\hline \multirow{2}{*}{ FATORES } & \multicolumn{2}{|c|}{ VAR. DEP. LO_AT } & \multicolumn{2}{c|}{ VAR. DEP. ROE_KE } & \multicolumn{2}{c|}{ VAR. DEP. P_VPA } \\
\cline { 2 - 7 } & ANOVA & ML & ANOVA & ML & ANOVA & ML \\
\hline Ano & $0,98 \%$ & $0,91 \%$ & $4,01 \%$ & $3,35 \%$ & $2,95 \%$ & $2,96 \%$ \\
\hline Indústria & $2,54 \%$ & $2,64 \%$ & $1,04 \%$ & $1,17 \%$ & $4,68 \%$ & $3,97 \%$ \\
\hline Indústria-ano & $2,07 \%$ & $2,47 \%$ & $3,39 \%$ & $4,77 \%$ & $2,44 \%$ & $2,03 \%$ \\
\hline Firma & $55,68 \%$ & $57,86 \%$ & $22,65 \%$ & $22,35 \%$ & $40,26 \%$ & $39,77 \%$ \\
\hline Modelo & $61,27 \%$ & $63,89 \%$ & $31,08 \%$ & $31,64 \%$ & $50,34 \%$ & $48,74 \%$ \\
\hline Erro & $38,73 \%$ & $36,11 \%$ & $68,92 \%$ & $68,36 \%$ & $49,66 \%$ & $51,26 \%$ \\
\hline
\end{tabular}

Nota: Os totais podem não coincidir devido ao arredondamento. Anova e ML são técnicas para a estimação das componentes de variância.

Tabela 4 - Teste de significância para 0 incremento de $\mathrm{R}^{2}$-ajustado.

\begin{tabular}{|l|c|c|c|c|}
\hline \multicolumn{1}{|c|}{ FATORES } & INCREM. $\mathbf{R}^{2}$ & F-INCREMENTO & P \\
\hline Ano & $1,20 \%$ & $0,70 \%$ & 1,04 & 0,3901 \\
\hline Indústria & $7,90 \%$ & $6,10 \%$ & 3,17 & 0,0000 \\
\hline Firma & $50,80 \%$ & $40,30 \%$ & 2,36 & 0,0000 \\
\hline Modelo & $59,90 \%$ & $47,10 \%$ & 2,48 & 0,0000 \\
\hline
\end{tabular}

Nota: A variável dependente do modelo é Fator1. 
mensuração da performance por múltiplos indicadores permite captar distintos efeitos da turbulência ambiental no desempenho das empresas. Neste estudo, três indicadores foram utilizados: uma medida de rentabilidade operacional; uma medida de geração de valor para o acionista; e uma medida das expectativas do mercado sobre os resultados futuros da empresa.

Os dados sugerem que essa mensuração multivariada não afetou a estrutura de variância do desempenho, e os resultados convergem para os de estudos anteriores, nos quais ficaram evidentes que as características da firma - seus recursos, competências e posicionamento competitivo - são os fatores mais importantes na descrição da variação do desempenho da firma. Em se tratando das características da estrutura setorial, estas contribuem secundariamente, sendo que os efeitos macroeconômicos se mostraram insignificantes.

Porém, a análise individualizada dos indicadores de desempenho revelou certas facetas da influência da turbulência ambiental nos resultados da empresa. A primeira é que a turbulência macroeconômica afeta distintamente os setores, e a estrutura de capital típica de um setor parece ser determinante na atratividade setorial mensurada pelo potencial de criação de valor para acionista.

A segunda faceta da influência da turbulência no desempenho da empresa se reflete no indicador do mercado, pois a lógica do investidor parece diferir da efetiva remuneração do capital investido. Pode-se inferir que determinadas indústrias possuem mecanismos para se proteger de medidas econômicas que afetem sensivelmente seu custo de capital, como, por exemplo, a captação de recursos a taxas mais baixas e a utilização de mecanismos de proteção às sucessivas desvalorizações cambiais. Por outro lado, a precificação das firmas no mercado recebe maior contribuição das características estáveis da indústria, onde os investidores estão buscando seguir mais o mercado do que o desempenho econômico e financeiro da empresa, comportamento característico de países emergentes, nos quais os fatores macroeconômicos nacionais e internacionais afetam as decisões dos investidores mais do que os resultados das empresas.

Em termos de geração de valor para o acionista, um setor atrativo seria aquele cujas características permitem às empresas proteger-se ou "blindar" suas estruturas de capital das turbulências econômicas. Já para o mercado, um setor atrativo é tradicionalmente bom para investir.

\section{Limitações e sugestões}

Como este estudo não esgotou o assunto, nem tinha a pretensão de fazê-lo, as direções para pesquisas futuras apontam para uma melhor especificação do modelo, bem como a inclusão da variável estrutura de capital parece atraente. Um próximo passo poderia incluir os fatores transientes da firma. Como ressalta Rumelt (1991), o termo de erro pode conter esses fatores. E como visto no caso de ambientes turbulentos, termos de interação com o ano parecem ser particularmente importantes. Outras especificações poderiam incluir medidas de performance baseadas no fluxo de caixa descontado ou que considerem o cálculo do retorno anormal por modelos de precificação de ativos. Poderia ainda incluir fatores como as alianças políticas e associações entre empresas e aprimoramento do design, formulando-se hipóteses de causalidade sobre a heterogeneidade da performance, visando superar as limitações de um modelo descritivo. O design também poderia ser aprimorado, formulando-se hipóteses de causalidade sobre a heterogeneidade do desempenho ou visando superar as limitações impostas pelo reduzido tamanho da amostra e pelos pressupostos do método de componentes de variância.

Enfim, espera-se que esta pesquisa incentive pesquisadores em estratégia no desenvolvimento de modelos aderentes às peculiaridades nacionais. Acreditase que ambientes turbulentos como o do Brasil são campos férteis para se descobrirem respostas acerca das diferenças sustentáveis entre a performance das firmas.

\section{NOTAS}

\footnotetext{
${ }^{1}$ As diferenças entre os percentuais se referem ao método utilizado. Rumelt (1991) utilizou o método COV (components-of-variance) para obter resultados comparáveis aos de Schmalensee (1985) e a ANOVA (analysisof-variance) para estimar e testar a significância de incrementos, na explicação da variância, proporcionados pela incorporação de cada fator no modelo.

${ }^{2}$ Pode-se argumentar que a redução pela ACP não confere significado à componente extraída. Os pesos de cada indicador são definidos pelo método e, a priori, não são derivados da teoria. Apesar dessa limitação, a redução pela ACP considera a variância comum, única e devida ao erro de mensuração, sendo indicada para decomposição de variância.

${ }^{3}$ Os efeitos transientes da indústria também captam variações de fontes endógenas, como as inovações tecnológicas. Contudo, neste artigo são focadas as fontes exógenas, especialmente a turbulência causada pela forte influência negativa do governo na economia.
} 


\section{REFERÊNCIAS BIBLIOGRÁFICAS}

BACIDORE, J. M.; BOQUIST, J. A.; MILBOURN, T. T.; THAKOR, A. V. The search for the best financial performance measure. Financial Analysis Journal, v. 53, n. 3, p. 11-20, 1997.

BAER, W. A economia brasileira. 4. ed. São Paulo: Nobel, 1996.

BARNEY, J. B. Strategic factor markets: expectations, luck, and business strategy. Management Science, v. 32, p. 1231-1241, 1986.

BRITO, L. A. L.; VASCONCELOS, F. C. Firm performance in an extremely turbulent environment: year, industry and firm effects. In: ENCONTRO NACIONAL DOS PROGRAMAS DE PÓS-GRADUAÇAO E PESQUISA EM ADMINISTRAÇAO, 27., 2003, Atibaia. Anais. Atibaia: ANPAD, 2003.

CAVES, R.; PORTER, M. From entry barriers to mobility barriers. Quarterly Journal of Economics, v. 91, p. 241-161, 1977

DOSI, G.; NELSON, R.; WINTER, S. (Orgs.). The nature and dynamics of organizational capabilities. New York: Oxford University Press, 2000.

HAIR, J. et al. Multivariate Data Analysis. 5. ed. New Jersey: Prentice Hall, 1995.

HAWAWINI, G.; SUBRAMANIAN, V.; VERDIN, P. Is performance driven by industry - or firm -specific factors? A new look at the evidence. Strategic Management Journal, v. 24, n. 1, p. 1-16, 2003.

MCGAHAN, A. M.; PORTER, M. E. How much does industry matter, really? Strategic Management Journal, v. 18, Summer Special Issue, p. 15-30, 1997.
MCGAHAN, A. M.; PORTER, M. E. What do we know about variance in accounting profitability? Management Science, v. 48, n. 7, p. 834-851, 2002.

OSTER, S. Modern Competitive Analysis. New York: Oxford University Press, 1990.

PETERAF, M. The cornerstones of competitive advantage: a resource-based view. Strategic Management Journal, v. 14, n. 3, p. 179-191, 1993.

PORTER, M. E. Competitive Strategy. New York: Free Press, 1980.

ROQUEBERT, J. A.; PHILliPS, R. L.; WESTFALL, P. A. Markets vs. management: what "drives" profitability? Strategic Management Journal, v. 17, n. 8, p. 653-664, 1996.

RUMELT, R. How much does industry matter? Strategic Management Journal, v. 12, n. 3, p. 167-185, 1991.

SCHMALENSEE, R. Do markets differ much? The American Economic Review, v. 75, p. 341-351, 1985

SEARLE, S. Linear Models. New York: John Wiley, 1971.

WERNERFELT, B. A resource-based view of the firm. Strategic Management Journal, v. 5, n. 2, p. 171-180, 1984.

WERNERFELT, B.; MONTGOMERY, C. A. Tobin's Q and the importance of focus in firm performance. The American Economic Review, v. 78, p. 246250,1988 .

Artigo recebido em 03.12.2004. Aprovado em 13.01.2006.

\section{Rodrigo Bandeira-de-Mello}

Professor da Universidade do Vale do Itajaí - Univali. Doutor em Engenharia de Produção pela Universidade Federal de Santa Catarina.

Interesses de pesquisa nas áreas de estratégia competitiva e desempenho organizacional.

E-mail: rmello@univali.br

Endereço: Rua Patrício Antônio Teixeira, 317, Jd. Carandaí, Biguaçu - SC, 88160-000.

\section{Rosilene Marcon}

Professora da Universidade do Vale do Itajaí - Univali. Doutora em Engenharia de Produção pela Universidade Federal de Santa Catarina.

Interesses de pesquisa nas áreas de estratégia competitiva e desempenho, finanças corporativas e mercado de capitais.

E-mail: rmarcon@univali.br

Endereço: Rua Patrício Antônio Teixeira, 317, Jd. Carandaí, Biguaçu - SC, 88160-000. 